\title{
SENSASI TERMAL PELAJAR DI DALAM RUANG KELAS
}

\author{
Humairoh Razak $^{1,{ }^{*}}$, Fitri Wulandari ${ }^{2}$ \\ ${ }^{1,2}$ Prodi Arsitektur, Fakultas Teknik, Universitas Muhammadiyah Banjarmasin, Barito Kuala, 70581 \\ *hrazak@umbjm.ac.id
}

Diterima: 15-11-2019 Direview : 16-11-2019_Direvisi: 7-12-2019_Disetujui: 27-12-2019

\begin{abstract}
ABSTRAK. Kota Banjarmasin memiliki iklim tropis lembab, kenyamanan termal menjadi unsur kenyamanan yang vital untuk dicapai khususnya untuk efektifitas kegiatan belajar bagi pelajar. Terutama dengan terjadinya pemanasan global, penggunaan penghawaan buatan seperti Air Conditioning (AC) justru akan memperparah terjadinya climate change karena AC merupakan salah satu sumber utama penghasil emisi. Metode pelaksaan penelitian ini dengan menggabungkan metode kuantitatif dan kualitatif. Metode kuantitatif digunakan untuk mengetahui kondisi termal di dalam dan di luar ruang kelas dengan mencari temperatur efektif kondisi termal di dalam ruang kelas dan kondisi iklim lingkungan sekolah dengan menggunakan alat environmental meter. Sedangkan metode kualitatif untuk mengetahui sensasi termal yang dirasakan pelajar saat berada di dalam ruang kelas, pengambilan data dilakukan 3 kali dengan interval 2 jam dimulai pukul 08.00 WITA. Hasil penelitian menunjukan bahwa sensasi termal yang dirasakan oleh pelajar pada pukul 08.00 dan pukul 10.00 WITA kurang dari $30 \%$ yang merasa nyaman saat berada di dalam ruang kelas dan tersisa hanya $5.14 \%$ pelajar yang merasa nyaman pada pukul 12.00 WITA. Puncaknya pada pukul 12.00 WITA saat matahari berada persis di puncak tertinggi $93.15 \%$ pelajar merasakan kepanasan, yaitu terasa agak panas, panas dan panas sekali. Hal ini didukung dengan data kuantitatif yang temperatur efektif di dalam ruang kelas berada di atas batas kenyamanan Webb, yaitu $30.58^{\circ} \mathrm{C}$ TE pada pukul 08.00 WITA, meningkat menjadi $31.38^{\circ} \mathrm{C}$ TE pada pukul 10.00 WITA dan puncak tertinggi pada pukul 12.00 WITA mencapai $31.57^{\circ} \mathrm{C}$ TE.
\end{abstract}

Kata kunci: Kenyamanan Termal, Temperatur Efektif, Lubang Udara, Ruang Kelas, Ventilasi Silang

ABSTRACT. Banjarmasin city has a humid tropical climate, which makes thermal comfort one of the vital comfort elements to be achieved. Especially for the effectiveness of the students' learning activities. Global warming is a hot topic today; the use of artificial ventilation such as air conditioning (AC) will aggravate climate change. $A C$ is one of the primary sources of global emission. This research used both quantitative and qualitative methods. The quantitative approach is used to determine thermal conditions inside and outside the classroom by finding the classroom's effective temperature and school environment using environmental meter tools. On the other hand, the qualitative method is used to determine student's thermal sensations inside the classroom. Data collection was carried out three times in 2-hour intervals starting at 08.00 WITA. The results showed that the students' thermal feeling inside the classroom at 8:00, and 10:00 WITA was less than 30\% who felt comfortable while only $5.14 \%$ felt comfortable at 12.00 WITA. The peak is at 12.00 WITA when the sun is precisely at the highest peak, $93.15 \%$ of students feel discomfort, which is feeling rather hot, hot, and very hot. This is supported by quantitative data where the effective temperature in the classroom is over Webb's comfort limit, which is $30.58^{\circ} \mathrm{C}$ ET at 08.00 WITA, increasing to $31.38^{\circ}$ $C$ at 10:00 WITA and the highest peak at 12.00 WITA reaching $31.57^{\circ} \mathrm{C} E T$.

Keywords: Thermal Comfort, Effective Temperature, Air Opening, Classroom, Cross Ventilation

\section{PENDAHULUAN}

Penggunaan energi pada bangunan banyak dipengaruhi oleh faktor iklim, kualitas iklim mikro di sekitar bangunan, arah bangunan, denah bangunan dan bahan bangunan (Handayani, 2010). Suhu udara yang relatif tinggi (hangat atau panas) dalam banyak hal cukup menguntungkan manusia yang tinggal di wilayah tropis, jika dilihat dari sudut pandang energi. Manusia tropis tidak memerlukan energi untuk pemanas ruang sebagaimana saudaranya yang tinggal pada iklim sub tropis (temperate) atau iklim dingin. Meskipun pada kondisi udara tertentu dengan suhu yang tidak dapat ditolerir manusia tropis memerlukan peralatan pengkondisian udara yang mengkonsumsi energi (Karyono, 2001).

Kutipan di atas menyebutkan bahwa faktor iklim menjadi penyebab utama penggunaan energi. Hal ini disebabkan kondisi iklim, khususnya di Banjarmasin dianggap kurang nyaman secara termal karena suhu rata-rata 
tahunan di Kota Banjarmasin adalah $27.8^{\circ} \mathrm{C}$ di atas standar temperatur efektif kenyamanan termal menurut Webb (Tabel 2). Bulan terpanas adalah Bulan April dengan suhu ratarata $28.3^{\circ} \mathrm{C}$. suhu udara tertinggi yang pernah tercatat adalah $42.8^{\circ} \mathrm{C}$ pada Bulan Februari.
Sedangkan bulan terdingin ada di Bulan Januari dengan suhu rata-rata $27.2^{\circ} \mathrm{C}$, dan suhu terendah yang pernah tercatat adalah $17.2^{\circ} \mathrm{C}$ pada Bulan Juli (Gambar 1 ).

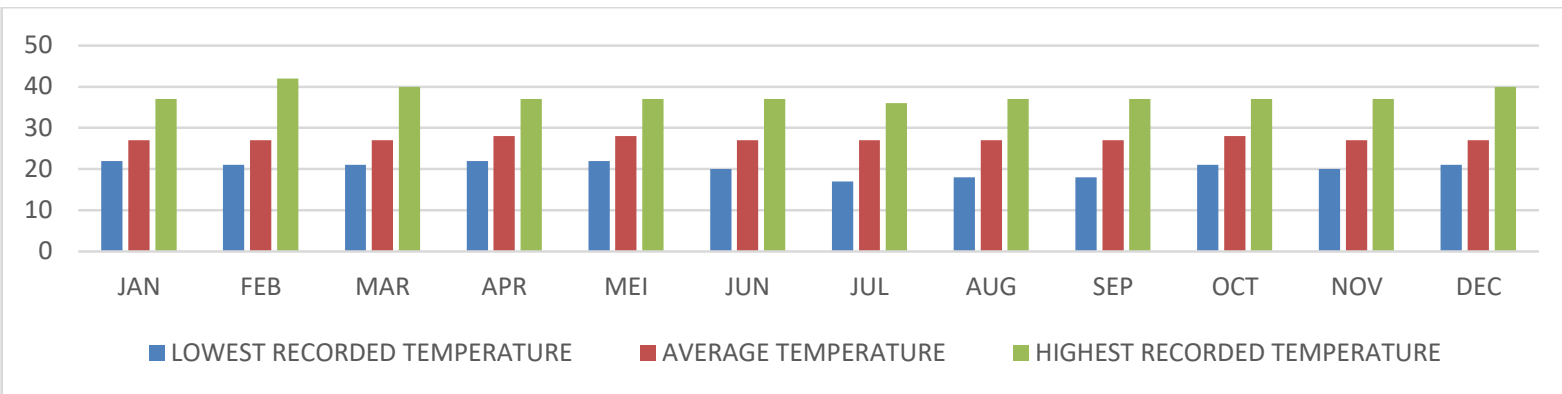

Gambar 1. Suhu Rata-Rata Kota Banjarmasin

(Sumber: www.weatherbase.com)

Selain suhu udara yang relatif tinggi, kondisi iklim tropis lembab juga ditandai dengan kelembaban udara yang relatif tinggi (Gambar 2). Perbedaan antar musim kemarau dan musim hujan hampir tidak ada kecuali pada periode musim hujan yang sering disertai angin kencang. Pada pagi hari kelembaban udara rata-rata yaitu $92 \%$ dan pada malam hari kelembaban rata-rata adalah $73.7 \%$.
Wilayah tropis lembab selain ditandai dengan suhu dan kelembaban udara yang relatif tinggi, juga ditandai dengan curah hujan yang tinggi pula. Kota Banjarmasin memiliki rata-rata curah hujan setahun $2575.6 \mathrm{~mm}$. Tertinggi pada bulan januari dengan $350.5 \mathrm{~mm}$ dan terendah pada bulan agustus dengan rata-rata 114.3mm (Gambar 3).



Gambar 2. Kelembaban Udara Rata-Rata Kota Banjarmasin.

(Sumber: www.weatherbase.com)

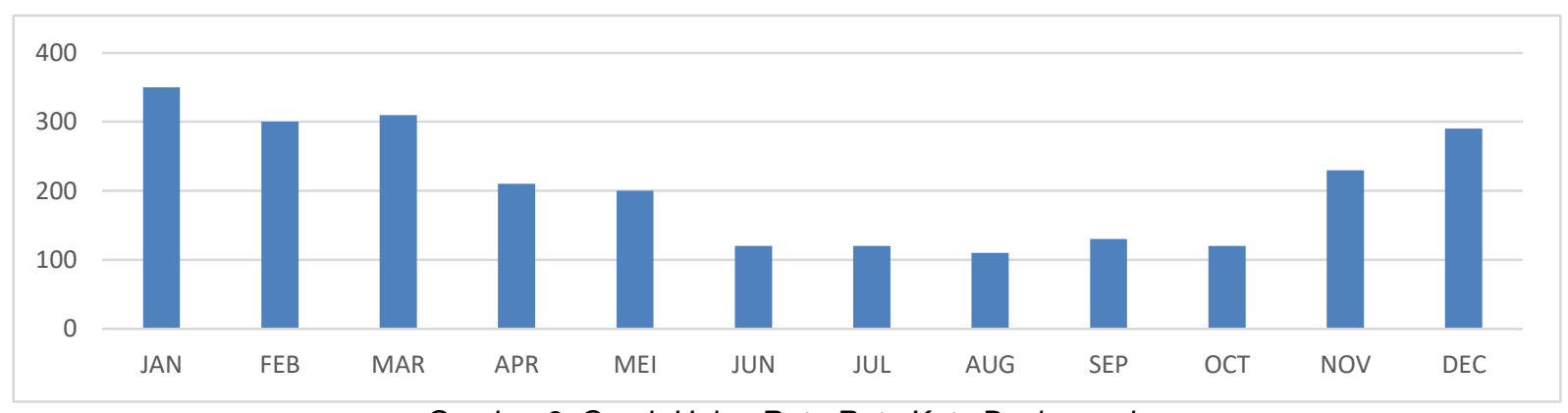

Gambar 3. Curah Hujan Rata-Rata Kota Banjarmasin

(Sumber: www.weatherbase.com)

Kenyamanan termal sendiri,untuk wilayah sekitar garis khatulistiwa berkisar antara $25^{\circ} \mathrm{C}$ $27^{\circ} \mathrm{C}$ sesuai dengan penelitian yang dilakukan C. Webb di Singapura. ASHRAE (American Society of Heating Refrigerating Air
Conditioning Engineer) memberikan definisi bahwa kenyaman termal adalah kondisi pikir yang mengekspresikan tingkat kepuasan seseorang terhadap lingkungan termalnya. ASHRAE menyatakan bahwa ada 4 unsur 
iklim dan 2 unsur individu yang memperngaruhi kenyamanan termal (Ashrae55, 2017), yaitu:

1. Suhu udara

2. Suhu radiasi

3. Kelembaban udara

4. Kecepatan angin

5. Aktifitas yang dilakukan

6. Jenis pakaian yang digunakan

Dalam penelitian ini karena dilakukan di sekolah-sekolah, maka pengguna ruangan utama (pelajar) menggunakan pakaian yang sama (seragam sekolah) dan melakukan kegiatan yang sama (duduk belajar). Berdasarkan pertimbangan tersebut maka 2 unsur individu dalam penelitian ini dihilangkan.

Sensasi termal menggunakan model PPD (Predicted Percentage of Dissatisfied) yaitu indeks yang memprediksi prosentase dari ketidakpuasan pengguna (orang) dengan skala sensasi termal yang merupakan skala psiko-fisik tujuh titik dari $-3,-2,-1,0,+1,+2,+3$ yang secara verbal disebut dingin sekali, dingin, sejuk/agak dingin, netral, hangat/agak panas, panas, dan panas sekali (Ashrae-55, 2017). Jelaslah bahwa 0 (netral) merupakan kondisi yang paling baik.

\section{METODE PENELITIAN}

Di Kota Banjarmasin terdapat 35 Sekolah Menengah Pertama Negeri. Namun obyek penelitian ini adalah 4 SMP Negeri yang tersebar di seluruh Kota Banjarmasin. Ratarata tiap sekolah diambil data 3 ruang kelas mewakili posisi ruang kelas terhadap arah angin (Gambar 4). Pengambilan data termal dan sensasi termal dilakukan sebanyak 3 kali dengan dari pukul 08.00 WITA dengan interval 2 jam, karena dirasa pada waktu-waktu tersebut ruang kelas paling sering digunakan untuk kegiatan belajar mengajar. Penelitian dilakakukan sekitar Bulan Juni-Juli, yang pada saat tersebut Kota Banjarmasin sedang Musim kemarau.


Gambar 4. Posisi Ruang Penelitian Sumber: Data Primer

Teknik pengambilan data termal di dalam ruang kelas dan di lingkungan sekolah (data kuantitatif) menggunakan instrumen penelitian yaitu Environmental Meter. Data termal yang diukur adalah suhu operatif (suhu udara dan suhu radiasi, $\left.{ }^{\circ} \mathrm{C}\right)$, kelembaban udara (\%RH) dan kecepatan angin ( $\mathrm{m} / \mathrm{s})$. Posisi pengambilan data termal dilakukan tepat di tengah ruang kelas (Gambar 5). Data termal indoor dan outdoor yang didapatkan akan digunakan untuk mencari temperatur efektif (TE) dengan aplikasi CBE Thermal Comfort Tool.

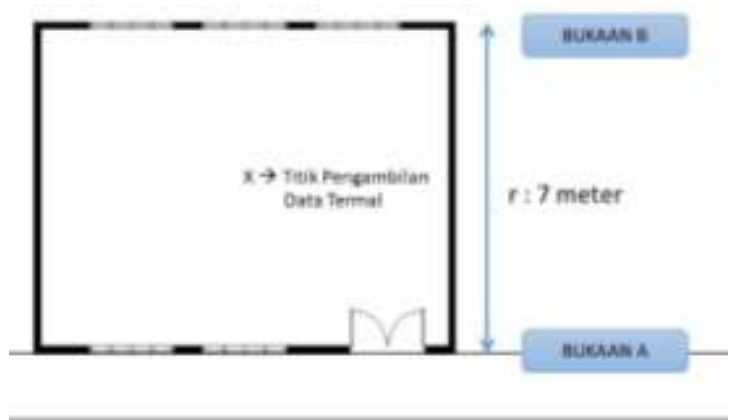

Gambar 5. Denah Ruang Kelas SMP Negeri Kota Banjarmasin (Sumber: Data Primer)

Teknik pengambilan data sensasi termal dengan kuisioner yang diisi pelajar saar berada di dalam ruang kelas. Total responden dalam penelitian ini berjumlah 525 pelajar. Kuisioner berupa tabel sensasi termal menggunakan model PPD (Predicted Percentage of Dissatisfied). Pelajar diminta untuk memberi tanda "X" pada salah satu kolom antara kolom dingin sekali, dingin, sejuk/agak dingin, netral, hangat/agak panas, panas, dan panas sekali sesuai dengan sensasi termal yang dirasakan pada pukul 08.00, 10.00 dan 12.00 WITA. 




Gambar 6. Dokumentasi Saat Pengambilan Data Kuantitatif dan Kualitatif di Dalam Ruang Kelas Sumber: Data Primer

Setelah data kualitatif terkumpul, seluruh data dikelompokan sesuai waktu pengambilan dan sensasi termal yang dirasakan pelajar. Kemudian dicari persentase tiap sensasi termal berdasarkan data keseluruhan setiap waktu pengambilan data.

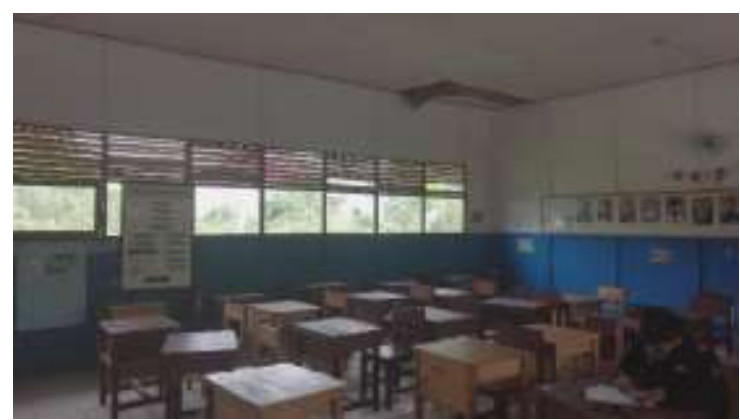

Gambar 7. Dokumentasi Saat Pengambilan Data Kuantitatif di Dalam Ruang Kelas

(Sumber: Data Primer)

\section{HASIL DAN PEMBAHASAN}

\section{Karakterisik Termal Lingkungan SMPN Kota Banjarmasin}

Temperatur efektif adalah fungsi dari radiasi panas, suhu, kelembaban dan pergerakan udara (Houghton \& Yaglou, 1923). Maka temperatur efektif sering digunakan sebagai parameter untuk mengukur kenyamanan termal. Batas kenyamanan termal berbedabeda sesuai dengan lokasi geografis dan subyek manusia yang diteliti (Lippsmeier \& Nasution, 1997)(Tabel 1).

Tabel 1. Batas Kenyamanan Termal dalam Skala

\begin{tabular}{cccc}
\multicolumn{4}{c}{ Temperatur Efektif } \\
\hline Pengarang & Lokasi & $\begin{array}{c}\text { Kelompok } \\
\text { Manusia }\end{array}$ & $\begin{array}{c}\text { Batas } \\
\text { Kenyamanan }\end{array}$ \\
\hline ASHRAE & USA $\left(30^{\circ} \mathrm{LU}\right)$ & Peneliti & $20,5^{\circ} \mathrm{C}-$ \\
& Calcuta & & $24,5^{\circ} \mathrm{C} \mathrm{TE}$ \\
Rao & $\left(22^{\circ} \mathrm{LU}\right)$ & India & $20^{\circ} \mathrm{C}-24,5^{\circ} \mathrm{C}$ \\
& & & $\mathrm{TE}$ \\
\hline
\end{tabular}

\begin{tabular}{cccc}
\hline Webb & Singapura & Malaysia & $25^{\circ} \mathrm{C}-27^{\circ} \mathrm{C}$ \\
& Khatulistiwa & Cina & $\mathrm{TE}$ \\
Mom & Jakarta & Indonesia & $20^{\circ} \mathrm{C}-26^{\circ} \mathrm{C}$ \\
& $\left(6^{\circ} \mathrm{LU}\right)$ & $\mathrm{TE}$ \\
Ellis & Singapura & Eropa & $22^{\circ} \mathrm{C}-26^{\circ} \mathrm{C}$ \\
& Khatulistiwa & $\mathrm{TE}$ \\
\hline \multicolumn{4}{l}{ Sumber: Lippsmeier \& Nasution, 1997}
\end{tabular}

Kondisi termal di lingkungan bangunan SMP Negeri Kota Banjarmasin yaitu temperatur efektif yang berkisar antara $28.7^{\circ} \mathrm{C}-30.5^{\circ} \mathrm{C}$ TE (Gambar 8). Sedangkan berdasarkan Tabel 2, batas kenyamanan termal di wilayah yang berdekatan dengan garis khatulistiwa seperti Singapura dan Banjarmasin adalah berkisar antara $25^{\circ} \mathrm{C}-27^{\circ} \mathrm{C} \mathrm{TE}$, maka dapat diambil kesimpulan bahwa kondisi iklim di lingkungan SMP Negeri Kota Banjarmasin berada di atas batas kenyamanan.

Pagi hari pukul 08.00 WITA, kondisi iklim di Kota Banjarmasin sudah melebihi dari batas kenyamanan termal yang maksimal $27^{\circ} \mathrm{C}$, yaitu $28.7^{\circ} \mathrm{C}$. Semakin matahari naik, maka semakin meningkat pula temperatur efektifnya, yaitu $29^{\circ} \mathrm{C}$ pada pukul 10.00 WITA dan $30.5^{\circ} \mathrm{C}$ pada pukul 12.00 WITA.



Gambar 8. Rata-Rata Temperatur Efektif Lingkungan SMPN Kota Banjarmasin (Sumber: Data Pribadi)

\section{Kenyamanan Termal Ruang Kelas SMPN Kota Banjarmasin}

Kondisi kenyamanan termal ruang kelas secara kuantitatif (Gambar 9). Temperatur efektif pada pukul 08.00 WITA mencapai $30.38^{\circ} \mathrm{C}$, pada pukul 10.00 WITA mencapai $31.38^{\circ} \mathrm{C}$, dan puncaknya pada pukul 12.00 WITA mencapai $31.57^{\circ} \mathrm{C}$. berdasarkan data tersebut jelaslah temperatur efektif di dalam ruang kelas pun berada di atas batas kenyamanan (Tabel 2). Selain berada di atas batas kenyamanan, kondisi termal ruang kelas juga berada di atas kondisi termal di luar ruang kelas (kondisi termal lingkungan sekolah). 


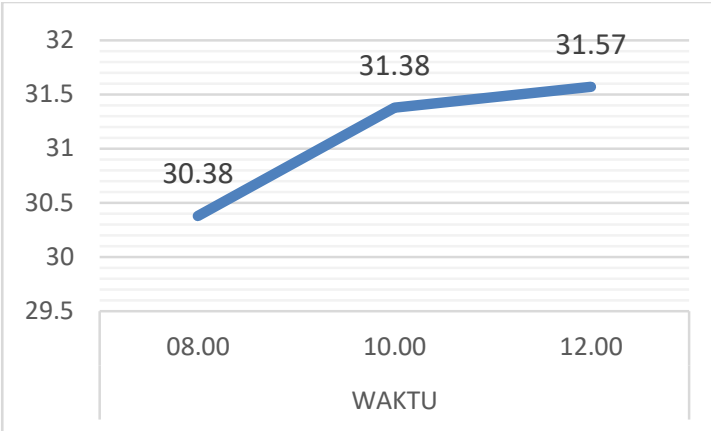

Gambar 9. Rata-Rata Temperatur Efektif di Dalam Ruang Kelas SMP Negeri Kota Banjarmasin

(Sumber: Data Primer)

\section{Sensasi Termal Pelajar di Ruang Kelas SMPN Kota Banjarmasin}

Sebagai manusia, adalah hal yang wajar untuk berkomentar terkait sensasi kenyamanan termal yang dirasakannya, bahkan untuk sekedar mengatakan kepanasan atau kedinginan. Pelajar menginformasikan ketidakpuasan atas kondisi termalnya dengan mengisi kuisioner yang sudah menunjukan dengan skala psiko-fisik tujuh titik dari -3, -2, $1,0,+1,+2,+3$ yang secara verbal disebut dingin sekali, dingin, sejuk/agak dingin, netral, hangat/agak panas, panas, dan panas sekali.

Sensasi termal pelajar selama berada di dalam ruang kelas, pada pukul 08.00 WITA hanya $28.38 \%$ yang merasa nyaman (netral). Kurang dari $1 \%$ merasakan panas sekali atau dingin sekali. Sensasi agak panas dirasakan oleh $16.38 \%$ pelajar dan $36.38 \%$ pelajar merasakan sensasi agak dingin.

Pada pukul 10.00 WITA, yang merasa nyaman semakin berkurang sekitar 3.05\% dari $28.38 \%$ pada pukul 08.00 WITA menjadi $25.33 \%$ dan yang merasa kepanasan semakin meningkat. Sensasi agak panas meningkat sekitar $25.53 \%$ menjadi $41.91 \%$. Pelajar yang merasakan panas meningkat $17.9 \%$ menjadi $19.81 \%$ dan pelajar yang merasakan panas sekali meningkat sebesar $0.95 \%$ menjadi $1.71 \%$. bertolak belakang dengan sensasi panas, pada sensasi dingin justru mengalami penurunan. Pelajar yang merasakan agak dingin pada awalnya sebesar $36.38 \%$ menurun cukup besar yaitu $27.81 \%$ menjadi hanya
8.57\% pelajar yang merasakan sensasi agak dingin. Sensasi dingin mengalami penurunan sebesar $12.76 \%$ menjadi $2.48 \%$. Sedangkan pelajar yang merasakan sensasi dingin sekali hanya tersisa $0.19 \%$.

Pada pukul 12.00 WITA, yang merasa nyaman semakin berkurang lagi sebesar $20.19 \%$ menjadi tersisa $5.14 \%$. Pelajar yang merasa panas sekali meningkat drastis sebesar $34.68 \%$ menjadi $36.39 \%$. sensasi panas juga meningkat sebesar $21.52 \%$ menjadi $41.33 \%$. Namun untuk sensasi agak panas justru mengalami penurunan sebesar $26.48 \%$ menjadi hanya $15.43 \%$, hal ini terjadi kemungkinan karena peningkatan drastis pada sensasi panas dan panas sekali, karena pada sensasi dingin semuanya mengalami penurunan persentase. Pada sensasi termal agak dingin persentase pelajar berkurang sebesar $7.43 \%$ menjadi $1.14 \%$. pelajar yang merasakan dingin berkurang sebesar $1.91 \%$ menjadi hanya sebesar $0.57 \%$. Sedangkan pelajar yang merasakan dingin sekali menjadi 0 (nol).

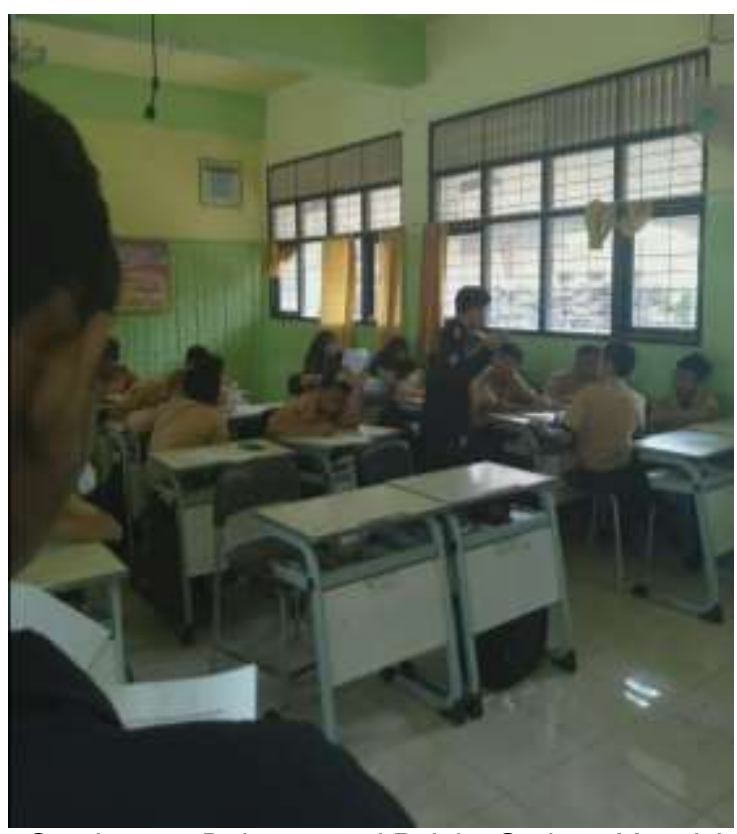

Gambar 10. Dokumentasi Pelajar Sedang Mengisi Kuisioner Dibantu Penjelasan dari Tim Surveyor. (Sumber: Data Primer) 




Gambar 11. Persentase Sensasi Termal Pelajar Terhadap Ruang Kelas.

(Sumber: Data Primer)

Berdasarkan penjabaran di atas, dapat dilihat bahwa semakin panas kondisi termal iklim lingkungan sekolah dan kondisi termal ruang kelas, maka semakin banyak pelajar yang merasakan "kepanasan" dan semakin berkurang persentase pelajar yang merasakan nyaman berada di dalam ruang kelas.

\section{Pengkondisian Kenyamanan Termal Indoor}

Berdasarkan hasil penelitian ini, akan lebih baik apabila dilakukan pengkondisian kenyamanan termal dengan cara alami. Secara arsitektural, ada beberapa cara yang dapat dilakukan (Alahudin, 2014), antara lain:

1. Perletakan bangunan terhadap matahari;

2. Perletakan bangunan terhadap arah angin;

3. Pemanfaatan elemen-elemen arsitektur dan lansekap; dan

4. Pemilihan pemakaian material bangunan sesuai dengan iklim.

Pemanfaatan elemen-elemen arsitektural seperti sistem ventilasi silang yang lebih ramah lingkungan dan murah dalam segi biaya. Sekilas pengamatan di lapangan, sistem ventilasi ruang kelas kurang mendukung terjadinya ventilasi silang, sehingga tim peneliti menyarankan untuk melakukan penelitian sistem ventilasi yang tepat untuk ruang kelas yang memaksimalkan ventilasi silang. Selain baik untuk kenyamanan termal, ada riset yang menunjukan bahwa rendahnya sirkulasi angin memberikan efek yang negatif bagi daya ingat dan daya konsentrasi pelajar hingga akhirnya berdampak buruk bagi kesehatan pelajar tersebut (Salleh et al., 2011).

\section{KESIMPULAN}

Berdasarkan pembahasan di atas, bahwa dapat diambil kesimpulan bahwa pada pukul 08.00 dan pukul 10.00 WITA kurang dari 30\% yang merasa nyaman saat berada di dalam ruang kelas dan tersisa hanya $5.14 \%$ pelajar yang merasa nyaman pada pukul 12.00 WITA. Puncaknya pada pukul 12,00 WITA saat matahari berada persis di puncak tertinggi $93.15 \%$ pelajar merasakan kepanasan. Walaupun data kualitatif merupakan data yang sangat subyektif toleransi termal masingmasing pelajar, namun ketidaknyamanan termal ruang kelas juga terbukti secara kuantitatif karena memiliki temperatur efektif ruang kelas yang berada di atas batas kenyamanan, yakni $30.58^{\circ} \mathrm{C}$ TE pada pukul 08.00 WITA, meningkat menjadi $31.38^{\circ} \mathrm{C}$ TE pada pukul 10.00 WITA dan puncak tertinggi pada pukul 12.00 WITA mencapai $31.57^{\circ} \mathrm{C}$ TE.

\section{UCAPAN TERIMA KASIH}

Terima kasih disampaikan kepada Kementrian Riset dan Teknologi Pendidikan Tinggi yang telah memberikan dukungan dana untuk pelaksanaan penelitian ini melalui skema Penelitian Dosen Pemula dengan waktu 1 tahun pada tahun 2019 , sehingga penelitian ini dapat berjalan dengan baik. 
Terima kasih juga disampaikan kepada semua pihak yang membantu selama proses berjalannya penelitian ini, khususnya Kepala Sekolah SMP Negeri Kota Banjarmasin yang mengizinkan dilaksanakannya penelitian ini di sekolah-sekolah Bapak/lbu dan Mahasiswa Program Studi S1 Arsitektur UM Banjarmasin yang melaksanakan pengambilan data lapangan.

\section{DAFTAR PUSTAKA}

Alahudin, M. (2014). Pengaruh Termal dalam Ruangan Perpustakaan Terhadap Kondisi Buku dan Kenyamanan Pembaca (Studi Kasus Perpustakaan Universitas Musamus Merauke). Jurnal IImiah Mustek Anim Ha, 3(2), 149-165.

Ashrae-55. (2017). ANSI/ASHRAE 55:2017 Thermal Environmental Conditions for Human Occupancy. Ashrae. https://doi.org/10.1007/s11926-011-02039

Handayani, T. (2010). Efisiensi energi dalam rancangan bangunan. Spektrum Sipil, 1(2), 102-108.

Houghton, F. C., \& Yaglou, C. P. (1923). Determining Equal Comfort Lines. Journal of American Society of Heating and Ventilating Engineers, 29, 165-176.

Karyono, T. H. (2001). Wujud Kota Tropis Di Indonesia: Suatu Pendekatan Iklim, Lingkungan Dan Energi. Dimensi Teknik Arsitektur, 29(2), 141-146. https://doi.org/https://doi.org/10.9744/dim ensi.29.2.

Lippsmeier, G., \& Nasution, S. (1997). Bangunan Tropis. Jakarta: Erlangga.

Salleh, N. M. ... Mahbob, N. S. (2011). Indoor Air Quality at School: Ventilation Rates and It Impacts Towards Children- A review. 2nd International Conference on Evironmental Science and Technology, 6(January), vol.6, 418-422. 
